\title{
Espécies e cultivares de Sanseviéria como plantas ornamentais
}

\author{
TICIANNY MELO DO NASCIMENTO ${ }^{1}$, TAÍS TOSTES GRAZIANO² \\ e CAMILA SCHULTZ LOPES ${ }^{3}$
}

\begin{abstract}
RESUMO
O gênero Sansevieria (Agavaceae) é constituído por cerca de 60 espécies e diversos cultivares, vulgarmente conhecidas como espada e lança-de-são-jorge, em vista de suas folhas achatadas lanceoladas ou cilíndricas, respectivamente. Além da sua utilização como planta fornecedora de fibras e de defesa, protetora contra mau-olhado (segundo crenças populares), muitas são, por excelência, de uso ornamental, cultivadas comercialmente como folhagens, sendo o seu fim determinado por seu hábito de crescimento e pela forma, textura e coloração de suas folhas. Além das qualidades estéticas, apresentam rusticidade adaptando-se a ambientes nem sempre favoráveis ao desenvolvimento da maioria das plantas. Apesar de seu cultivo ser bastante antigo, ainda é pequena a sua utilização quer em canteiro, quer mesmo em vaso. $\mathrm{O}$ trabalho tem o objetivo de despertar o interesse para o seu uso, levantando também seu potencial como folhagem de corte, para arranjos florais.
\end{abstract}

Palavras-chave: folhagem, espada e lança-de-são-jorge, floricultura.

\section{ABSTRACT \\ Species and cultivars of Sansevieria as ornamental plants}

The genus Sansevieria (Agavaceae) is made of sixty species and different cultivars coming from hybridization. They are normally known as "snakes plants", "bowstring hemp" and" "mother-in-law's tongue" because of the shape of their leaves, flattened, lanceolate or cylindrical. In spite of their utilization as fibber producer and as a defence against "bad luck" (according to some popular beliefs), many species and their cultivars are ornamental, commercially grown as foliage, with a variation of the usage, according to their growth habit, shape, texture and colors of their leaves. Besides their esthetical qualities, they are rustic and can be adapted to a wide range of areas, even the ones less favorable to the cultivation of many others species. Although species of Sansevieria have been cultivated for a long time, their potential has not been explored, neither in beds nor as potted plants. This article aims to provide the increase of interest in sansevieria usage, showing their potential as foliage plant, in floral art.

Key words: foliage, snake plants, floriculture.

\section{INTRODUÇÃO}

A indústria da floricultura tem como característica básica a permanente busca por novidades que possam ser lançadas no mercado. Isso acontece basicamente mediante trabalhos de melhoramento genético de plantas, com a criação de novos cultivares ou com a introdução e seleção de novos materiais com características favoráveis. No entanto, existe uma gama imensa de produtos que ficam esquecidos no tempo, fora de moda, como se costuma dizer, que podem voltar ao mercado, bastando, para isso, que se proponha uma forma diferente de uso, que alguém de renome e formador de opinião passe a utilizá-la ou, ainda, que algum produtor invista mais maciçamente na sua divulgação. Isso

\footnotetext{
${ }^{1}$ Engenheira Agrônoma Mestranda em Agricultura Tropical e Subtropical - IAC, Caixa Postal 28, 13001-970 Campinas (SP). E-mail: ticianny@hotmail.com

${ }^{2}$ Instituto Agronômico - Centro APTA de Horticultura - IAC, Caixa Postal 28, 13001-970 Campinas (SP). E-mail: tais@iac.sp.gov.br

${ }^{3}$ Engenheira Agrônoma M.Sc. em Agricultura Tropical e Subtropical - IAC. E-mail: camilasl@yahoo.com
} 
normalmente tem ocorrido com muitas plantas consideradas "antigas" e que acabam voltando "na moda". São exemplos, entre outras, as Cycas, algumas variedades de Rosa, muitas plantas com flores perfumadas (jasmim e gardênia), begônias (Begonia spp.), tinhorões (Caladium $x$ hortulanum).

Existem outros produtos, ainda, que, apesar de nunca terem caído em desuso, têm uma produção pouco expressiva comparada ao seu potencial de uso, como é o caso de espécimes das plantas aqui tratadas. O gênero Sansevieria, cujas plantas são popularmente conhecidas por espada e lança-de-são-jorge, pertence à família Agavaceae (JOLY, 1977), porém essa classificação pode variar de acordo com o sistema adotado. Alguns autores as classificam como pertencentes à família Liliaceae (GRAF, 1978; LORENZI \& MELLO FILHO, 2001), outros, Dracaenaceae (DAHLGREN et al., 1985) e ainda, como Convallariaceae (THE LINNEAN SOCIETY OF LONDON, 2003). No presente trabalho, serão denominadas pelo nome popular sansevieria, para facilitar a descrição das espécies do gênero.

De origem africana, foram introduzidas pelos escravos no Brasil, onde, a princípio, eram cultivadas para o aproveitamento da fibra de suas folhas, de característica resistente. A história também acrescenta a sua utilização para chicotear animais de carga no Estado da Bahia, o que, provavelmente, tenha contribuído para a disseminação dessas plantas, já que, depois de desgastadas, as folhas eram jogadas e ali mesmo enraizavam facilmente, dando origem a uma nova planta (BLOSSFELD, 1963).

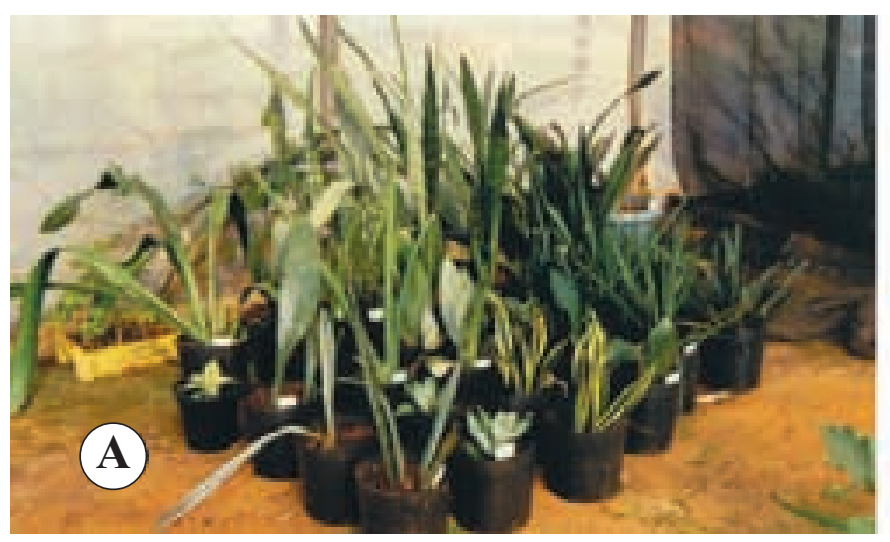

\section{CLASSIFICAÇÃO BOTÂNICA E MORFOLOGIA}

O gênero Sansevieria é constituído de, aproximadamente, sessenta espécies de origem africana, arábica e indiana. Muitas delas e seus cultivares têm, por excelência, caráter ornamental, sendo cultivadas comercialmente para uso como folhagens, com o seu fim determinado por seu hábito de crescimento, textura e coloração da planta (HENLEY et al., s.d.).

Segundo LORENZI \& MELLO FILHO (2001), são plantas herbáceas, rizomatosas, com folhas geralmente eretas, suculentas, fibrosas, de coloração que varia do verde mais claro ao mais intenso. Algumas apresentam variações na mesma folha, formando estrias esbranquiçadas ou amarelas. Outras, como ocorre normalmente nas espécies variegadas, possuem a borda das folhas amarelo-douradas, em vista de um fenômeno genético conhecido por quimera.

Conforme pode ser visto na Figura 1, as sanseviérias variam muito no hábito e na forma de crescimento. Algumas são plantas pequenas, de folhas curtas, carnosas e espessas, enquanto outras possuem folhas longas, delgadas e coriáceas. Outras, como a $S$. singularis, são caracterizadas por folhas cilíndricas e separadas entre si, em contraste com aquelas de folhas semicilíndricas, dispostas em forma de leque. Existem também espécies arborescentes, com folhas emergindo de um caule curto e espesso (MEDINA, 1959).

A altura das folhas varia entre 15 e $140 \mathrm{~cm}$ de comprimento. A inflorescência é um racemo, que ge-

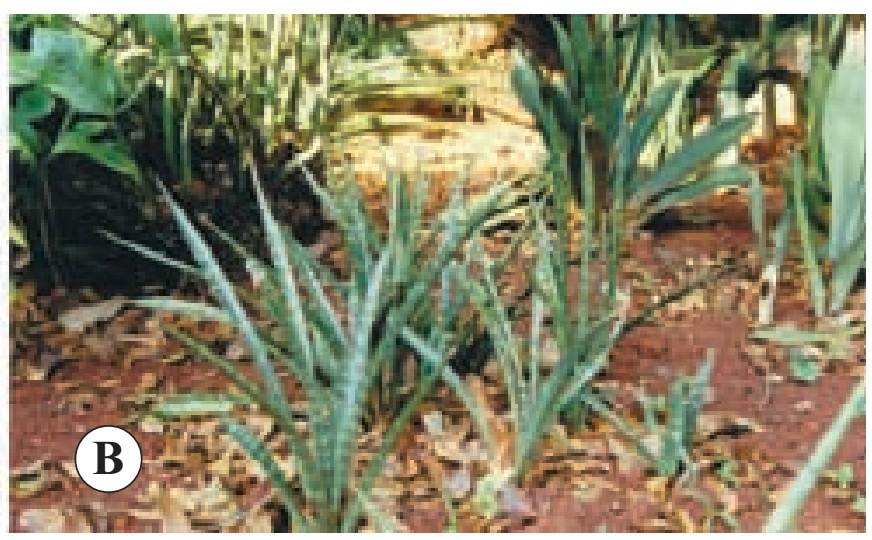

Figura 1. Coleção de espécies e cultivares de Sansevieria em vasos (A) e em plantio no solo (B), do Centro APTA de Horticultura - IAC, Campinas, mostrando a diversidade de formas encontradas em cultivo. 
ralmente se origina na axila das folhas (LORENZI \& MELLO FILHO, 2001), de beleza admirável em algumas espécies (HERWIG, 1976). As flores possuem um perigônio em dois ciclos (cálice e corola) idênticos e soldados entre si; a coloração predominante é branca (ora amarelada, ora esverdeada). Os frutos são carnosos do tipo baga.

\section{ESPÉCIES CULTIVADAS}

\subsection{Sansevieria trifasciata Hort. ex Prain}

Nativa da África do Sul, essa espécie forma densas touceiras, atingindo altura entre 30 e $70 \mathrm{~cm}$. As folhas são dispostas verticalmente, laminares, lanceoladas, coriáceas e glabras em ambas as faces. A cor é verde-escura, com bandas transversais verde-acinzentadas e brancas, de largura variável entre 5 e $8 \mathrm{~cm}$. As inflorescências apresentam flores perfumadas, branco-esverdeadas (LORENZI \& MELLO FILHO , 2001).

A $S$. trifasciata apresenta um bom número de variedades e cultivares, entre eles:

\section{a. Sansevieria trifasciata var. laurentii (De Wild.) N.E. Br}

Planta descoberta no Congo, África Central, por volta dos anos vintes, suporta as mais severas adversidades. É tolerante ao sol e à sombra, excesso ou falta de água. Só começa a justificar sentir os rigores da temperatura quando ela diminui excessivamente (ANDREU, 1975).

De acordo com LORENZI \& MELLO FILHO (2001), essa variedade apresenta folhas espessas com altura que varia de 70 a $90 \mathrm{~cm}$. Sua coloração é verde-acinzentada, com manchas verde-claras transversais, podendo apresentar margens creme-amarelado. São indicadas para o cultivo em vasos ou formando bordaduras, com boa resistência a solos áridos e ao calor tropical, bem como ao frio.

\section{b. Sansevieria trifasciata Pain 'Hahnii'}

Essa variedade anã surgiu por mutação espontânea nos Estados Unidos, durante a Segunda Guerra Mundial (BLOSSFELD, 1963), resultante de mutação hortícola da espécie típica ( $S$. trifasciata) (LORENZI $\&$ SOUZA, 2001). Apresenta folhas pequenas, com altura variável entre 15 e $20 \mathrm{~cm}$, com um bonito colorido em forma de mosaico, verde-acinzentado com verde-escuro, que se agrupam como uma roseta. Essa particularidade empresta à planta uma aparência graciosa $\mathrm{e}$ muito delicada que a diferencia das outras variedades de espada-de-são-jorge, que, embora bonitas, têm uma aparência mais agressiva (http://jabasta.net/arq/secoes/ jardtopicosdecorativas03.html).

Segundo LORENZI \& SOUZA (2001), são apropriadas para bordaduras, forrações ou conjuntos isolados, à meia-sombra ou a pleno sol, de grande efeito decorativo. A forma variegada, Sansevieria trifasciata 'Golden Hahnii', tem tendência a retroceder à forma original, de cor verde. Não toleram o frio nem costumam florescer.

\section{c. Sansevieria trifasciata Prain \\ 'Bantel's Sensation'}

Nativa da África do Sul, conhecida por "espadinha", apresenta rizomas suculentos e folhas que atingem 40 a $60 \mathrm{~cm}$ de altura. Suas folhas são lineares, côncavas ou canaliculadas, coriáceas e grossas, lustrosas, glabras e variegadas com faixas longitudinais de larguras variáveis brancas em fundo verde, de 4 a $6 \mathrm{~cm}$. Planta muito resistente à seca, porém bem sensível ao frio invernal e às geadas (LORENZI \& MELLO FILHO, 2001).

HENLEY et al. (s/d) ainda destacam para fins ornamentais a Sansevieria trifasciata 'Futura', que é similar a $S$. trifasciata var. laurentii, porém mais compacta; a S. trifasciata 'Moonshine', S. trifasciata 'Robusta' e S. trifasciata 'Nelsonii'. GRAF (1978) acrescenta ainda a S. trifasciata 'Craigii' de folhas mais longas e flexíveis e $S$. trifasciata 'Goldiana', muito parecida com a laurentii, mas com, além de bordas laterais amarelo-creme, uma faixa estreita de cor creme, vertical, adicional.

\subsection{Sansevieria cylindrica Bojer}

Espécie muito decorativa usada na África como matéria-prima para a fabricação de fibras. De acordo com BLOSSFELD (1963), é encontrada em jardins, apresentando folhas verdes e roliças, finalizadas em ponta curta e dura.

É originária da África Tropical e sua altura varia de 50 a $90 \mathrm{~cm}$. Suas folhas são cilíndricas, longas, pontiagudas, suculentas, com manchas branco-acizentadas e sua inflorescência, ereta, firme e branco-rósea (LORENZI \& SOUZA, 2001).

\subsection{Sansevieria ehrenberguii Schweinf. ex Baker}

Nativa da Etiópia, Quênia e Tanzânia, é uma planta entoucerada, de caule curto e altura entre 40 e $60 \mathrm{~cm}$. Conhecida popularmente como sanseviéria-leque, é 
caracterizada pelo arranjo alternado das folhas como um grande leque (GRAF, 1978). Suas folhas, canaliculadas, achatadas nas margens e arredondadas no meio, quando sombreadas tornam-se verde-azuladas. É bem indicada para composição de jardins de pedra, principalmente pela rusticidade, com resistência à seca e à intensa insolação do nosso verão (LORENZI \& MELLO FILHO, 2001).

\subsection{Sansevieria zanzibarica Gerome \& Labroy}

Originária da Tanzânia, apresenta-se com 60 a 140 $\mathrm{cm}$ de altura. As folhas são reunidas em tufos, cilíndricas, longas, rígidas e pontiagudas, com manchas amarelo-acinzentadas e 3 a $5 \mathrm{~cm}$ de diâmetro. Pode ser diferenciada da $S$. cilyndrica pelas folhas mais longas e mais grossas. As inflorescências são eretas e firmes, com flores esbranquiçadas e, como fator ornamental, de importância secundária. É uma planta rústica que resiste bem à seca e à insolação intensa (LORENZI \& MELLO FILHO, 2001).

\subsection{Sansevieria fasciata Cornu ex Gerome \& Labroy}

Nativa da África Tropical, a espécie apresenta-se com 30 a $60 \mathrm{~cm}$ de altura e margens corticosas com largura de 7 a $9 \mathrm{~cm}$. Suas folhas são dispostas geralmente aos pares, grossas e suculentas, rígidas, lustrosas a opacas, verde-acinzentadas, com manchas transversais em ziguezague verde-claras. A inflorescência atinge de 10 a $15 \mathrm{~cm}$ de comprimento, emergindo de escapos curtos (LORENZI \& MELLO FILHO, 2001).

\subsection{Sansevieria senegambica Baker}

Originária do Senegal e Gâmbia (GRAF, 1978), de folhas verde-acinzentadas com um canal côncavo na base, é, algumas vezes, ligeiramente listrada ao longo da borda (HERWIG, 1976).

\subsection{Sansevieria splendens Stapf}

Conhecida popularmente como "espada-larga" por suas folhas largas, carnosas, grossas, de superfície côncava, verde-escura azulada, com fraca marmorização e 30 a $60 \mathrm{~cm}$ de altura. É uma planta nativa da África Tropical, apropriada para o cultivo em jardins de pleno sol, em regiões tropicais e subtropicais (LORENZI \& MELLO FILHO, 2001).

\subsection{Sansevieria longiflora Sims}

É dotada de uma folhagem verde-escura, belamente marmorizada, e uma admirável inflorescência (HERWIG, 1976).

\subsection{Sansevieria dawei Stapf}

Nativa da África tropical, é uma planta bem entouceirada, de 30 a $50 \mathrm{~cm}$ de altura. Suas folhas são eretas, laminares, grossas, lanceoladas, verde-escuras e levemente manchadas de verde-claro na face superior. Bastante indicada para a formação de maciços e renques tanto a pleno sol como à meia-sombra. Também indicada para vasos e jardineiras para interiores iluminados (LORENZI \& MELLO FILHO, 2001).

\subsection{Sansevieria powellii N. E. Br.}

Planta arborescente, forma densas colônias de ramos enfolhados eretos, chegando a $1 \mathrm{~m}$ de altura. Folhas caneladas, curtas, de um verde-azulado escuro quando em cultivo e mais amarelado no seu habitat (deserto do Quênia) (GRAF, 1978), semelhante a $S$. arborescens.

\subsection{Sansevieria thyrsiflora Thunb.}

Suas folhas são lançadas em rosetas, de 40 a 60 $\mathrm{cm}$ de altura, formadas por cerca de 20 folhas rígidas, estreitas, angularmente caneladas, de um verde-acinzentado escuro e flores branco-esverdeadas, perfumadas (GRAF, 1978).

\subsection{Sansevieria pinguicula Lillian \& Leo Pickoff}

De acordo com GLAVICH (2001), a planta, originária do Quênia, tem desenvolvimento lento. Suas folhas curtas e duras, crescem em forma de roseta. Normalmente, surgem de uma a três folhas da superfície do rizoma, atingindo uma altura até de $60 \mathrm{~cm}$, eretas, recurvadas para trás, verde-acizentadas escuras (CHAHINIAN, 2003).

\section{UTILIZAÇÃO COMO PLANTAS ORNAMENTAIS}

Pelas características já descritas, as espécies de Sansevieria têm sido utilizadas em ambientes mais rústicos, que oferecem normalmente limitações ao desenvolvimento da grande maioria das plantas, tanto em ambientes de interior como de exterior. Segundo HERWIG (1976), essas plantas entraram em nossas casas há muito tempo, não perdendo mais a sua popularidade, pela sua natureza até certo ponto suculenta, sendo resistentes a eventuais negligências, além de oferecer a vantagem de serem tolerantes à baixa umidade do ar, razão pela qual podem ser indicadas para ambientes com ar condicionado. 
Podem ser cultivadas a pleno sol e utilizadas tanto em vasos quanto em bordaduras ou maciços (LORENZI \& MELLO FILHO, 2001). São plantas interessantes e bem recomendadas na composição de jardins, inclusive os pedregosos, pela rusticidade e forma característica de suas folhas, além da resistência à seca.
Além do seu uso como plantas ornamentais, são também conhecidas como plantas de "defesa", vindo a compor o conhecido "vaso das sete ervas", encontrado no mercado como um arranjo de plantas que protegem os ambientes contra o "mau-olhado". Acredita-se que o perfume exalado influencia as reações das pessoas.
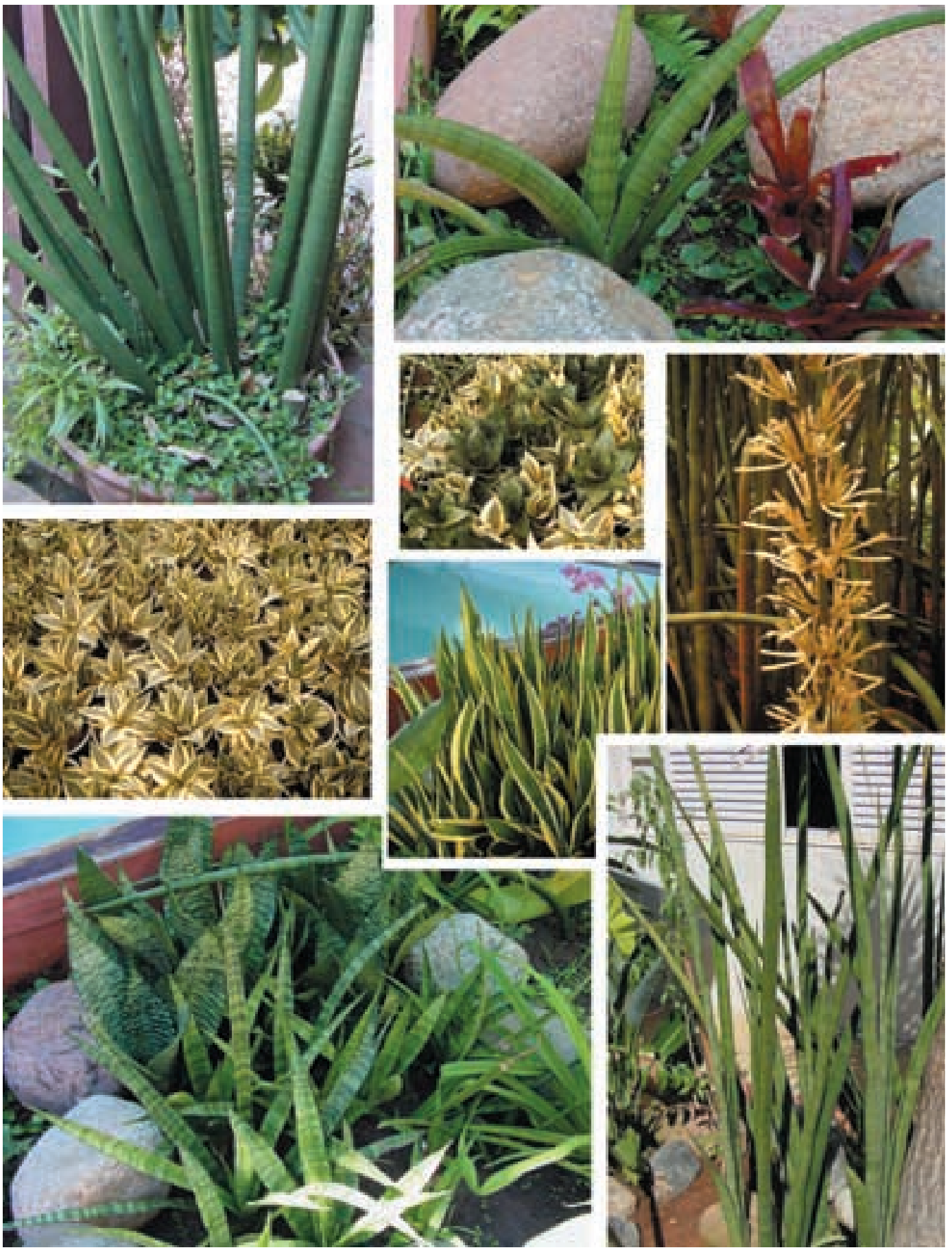

Figura 2. Utilização de diferentes espécies e cultivares de Sansevieria como planta envasada e na formação de canteiros. 
As principais plantas usadas são arruda, alecrim, guiné, alfazema, espada-de-são-jorge e comigo-ninguém-pode (BUONFIGLIO, 2001). Segundo a crença popular, são indicadas para a porta de entrada, do lado de fora das casas. Fortes, bonitas e perfumadas, protegem a casa contra a inveja e os maus espíritos e, quando plantadas lado a lado, formam uma barreira contra as energias negativas (http://www.destinos.com.br/sintonia).

Mais recentemente, algumas espécies e cultivares têm-se despontado como folhagem para corte, utilizadas na composição de arranjos florais, destacando-se, principalmente, pela sua durabilidade após o corte. Segundo TAKAWIRA \& NORDAL (2002), há também espécies utilizadas para fins medicinais.

Roberto Burle Marx sempre teve um carinho grande por essas plantas, mantendo uma coleção considerável em seu sítio em Guaratiba (RJ), onde as mantinha em canteiros de frente a sua residência, compondo com bromélias, entre outras, sobre pedras.

A Figura 2 apresenta algumas das espécies mais cultivadas como plantas ornamentais, dando especial destaque a suas formas mais comuns de utilização.

\section{PROPAGAÇÃO}

A escolha do melhor método de propagação das sanseviérias depende da variedade e morfologia de cada planta. Embora muitas espécies possam ser propagadas por sementes, essa técnica não é muito utilizada pela grande quantidade necessária para atender à produção comercial (HENLEY et al., s/d). O mais empregado comercialmente na multiplicação dessas plantas é o método assexuado, por divisão de touceiras e estaquia, tanto de rizomas como de folhas, dependendo da espécie, do cultivar e do tamanho da planta desejada (HERWIG, 1976). As espécies com órgãos subterrâneos maiores podem ser propagadas por divisão de rizomas, enquanto aquelas de parte aérea mais desenvolvida, também por estacas foliares. A Figura 3 apresenta a multiplicação de Sansevieria sp. pelo uso de sementes e a brotação em estacas foliares de $S$. trifasciata.

\subsection{Sementes}

As sementes são colocadas em um meio para semeadura, em viveiro, a $2,5 \mathrm{~cm}$ de profundidade, espaçadas de $5 \times 10 \mathrm{~cm}$. Dentro de 30 a 40 dias, dá-se início à germinação. As plantas oriundas de sementes desenvolvem-se mais lentamente que aque- las provenientes de estacas obtidas de folhas (MEDINA, 1959).

\subsection{Divisão de touceiras}

Trata-se de um método de propagação geralmente utilizado em plantas rizomatosas, bastante comum em sanseviérias. Consiste na separação das novas brotações que surgem do rizoma subterrâneo, podendo variar de acordo com o tipo de rizoma. Algumas espécies produzem brotações bem próximas da planta original, apresentando um crescimento mais adensado. Já outras produzem brotações mais distanciadas, ocupando áreas maiores.

As plantas obtidas dessa forma atingem a máxima produção, como ornamentais, entre um ano e meio a dois anos depois do plantio, dependendo do espaçamento, adubação, irrigação e quantidade de plantas colhidas (HENLEY et al., s.d.). As brotações devem ser retiradas com um número de folhas suficiente para que possam alcançar o máximo desenvolvimento em menor tempo (MEJIAS \& RUANO, 1990).

\subsection{Estaquia}

\section{a. Estaquia de rizoma}

Esse tipo de estaquia é feito quando rizomas são segmentados em pedaços contendo, pelo menos, uma gema lateral. O tamanho das estacas depende da espécie ou cultivar, uma vez que há grande variação no comprimento e diâmetro, assim como no hábito de crescimento dos rizomas produzidos. Não é o procedimento mais usual de propagação, sendo demorado e, muitas vezes, fadado ao insucesso.

\section{b. Estaquia de folhas}

Outra forma de estaquia utilizada é por intermédio de secções da folha, cujo tamanho é determinado pelo hábito de crescimento da planta. Para os cultivares anãos, como Sansevieria trifasciata 'Hahnii', são utilizadas folhas inteiras de 7,5 a $10 \mathrm{~cm}$ de comprimento, enquanto as plantas de folhas maiores são cortadas em secções de 10 a $20 \mathrm{~cm}$. Quanto menores as porções, maior o tempo necessário na propagação (HENLEY et al., s.d.).

As estacas devem ser enterradas com a sua parte basal para baixo, aproximadamente de 2,5 a $3,8 \mathrm{~cm}$ da estaca, em um substrato úmido, mas bem drenado. Para o enraizamento, o ideal é que a temperatura esteja em torno de $20^{\circ} \mathrm{C}$ (MEJIAS \& RUANO, 1990). 


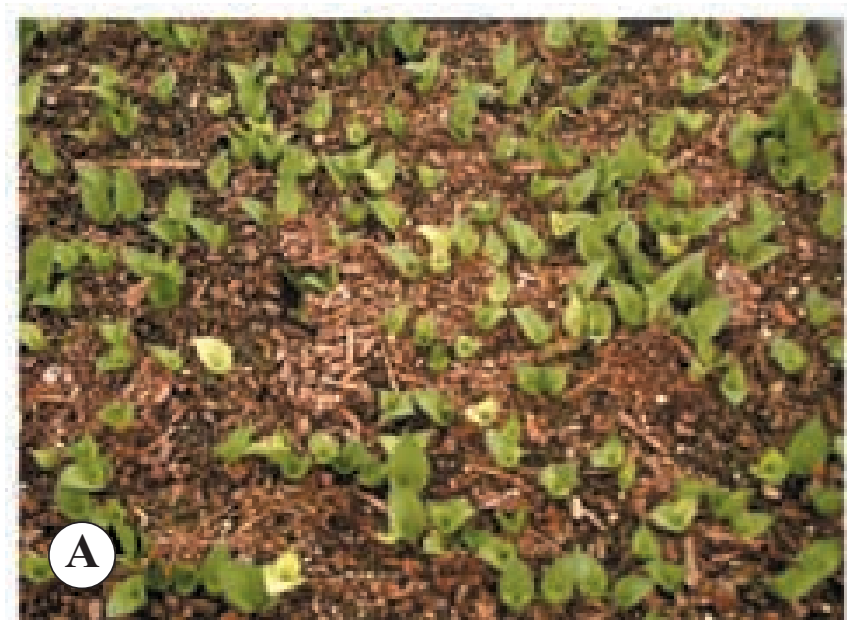

Figura 3. Germinação de sementes de Sansevieria sp.

As raízes começam a desenvolver-se após 4 a 6 semanas e uma ou mais folhas emergem da superfície do meio de propagação em 3 a 4 meses (Figura 4). Dependendo do cultivar, do tamanho e da posição da folha em que foi retirada a estaca e da sua condição fisiológica, sob condições favoráveis, um propágulo pode originar de uma a cinco mudas, que devem ser separadas quando atingirem o tamanho desejado (HENLEY et al., s.d.; MEDINA, 1959).

De acordo com HARTMANN et al. (1990), nas espécies de Sansevieria variegadas podem ocorrer variações genéticas conhecidas como quimeras, nas quais tecidos com e sem mutações ocupam lugares distintos no mesmo vegetal, divididos em camadas ou secções. Essas mutações geram características na planta que, muitas vezes, deseja-se manter, nos casos de propagação clonal dessas espécies. Em tais plantas, partes do

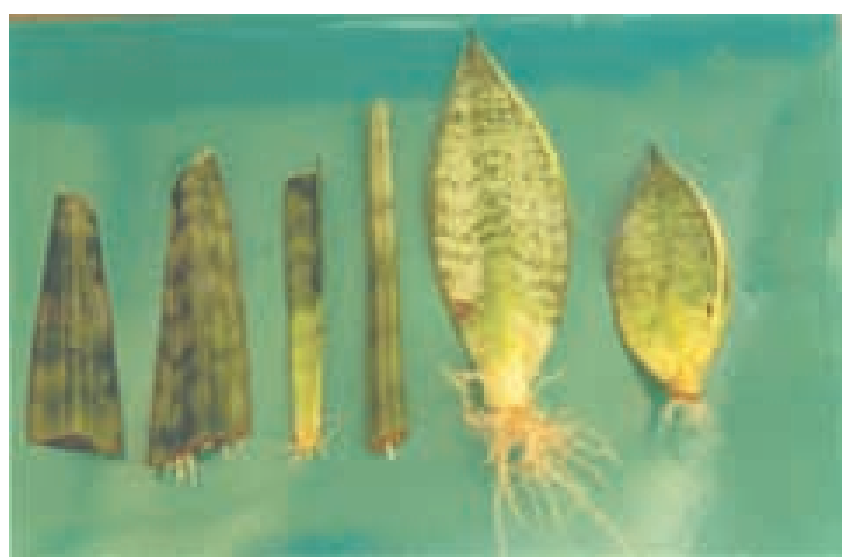

Figura 4. Estacas foliares enraizadas: folhas inteiras de Sansevieria trifasciata 'Hahnii' e folhas segmentadas de três outras espécies.

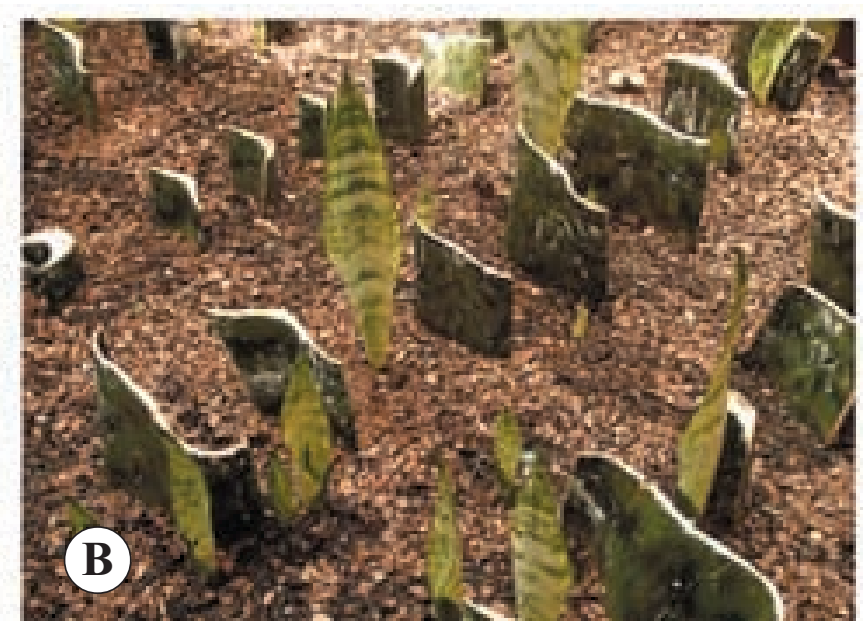

(A) e brotação de estacas foliares de S. trifasciata (B).

tecido vegetal perdem a capacidade de produzir clorofila, enquanto outras se mantêm normais, causando colorações distintas na mesma folha.

Em algumas espécies de Sansevieria são encontradas quimeras do tipo periclinal que consistem em uma camada superficial e delgada de tecido (pele), com uma composição genética, recobrindo um núcleo formado por células com tipo genético diferente, ou seja, o tecido com mutação está localizado numa fina camada, geralmente epidérmica, que recobre uma porção de tecido inalterado. Esse é o tipo de quimera mais comum e estável. A propagação de uma quimera periclinal por alguns tipos de estacas de folhas, como em plantas de $S$. trifasciata var. laurentii, pode resultar numa reversão à forma não mutante, perdendo, nesse caso, a variegação nas folhas, uma vez que a planta originada será obtida por desenvolvimento do tecido endógeno. Por isso, para que esse cultivar mantenha as características desejadas, deve-se evitar a propagação por estaquia de folhas, sendo mais indicada a divisão de touceira (HARTMANN et al., 1990).

\section{CONDIÇÕES DE CULTIVO}

Todas as espécies são rústicas, adaptando-se muito bem ao sol ou à sombra, ao calor e ao frio, sendo sensíveis apenas ao encharcamento da terra e ao frio excessivo (BLOSSFELD, 1963).

É uma planta muito fácil de cultivar, não exigindo requisitos especiais, mas o sol intenso pode afetar o desenho da folhagem (HERWIG, 1976). Na fase de produção, a luminosidade ideal deve estar entre 20.000 e 35.000 lux (MEJIAS \& RUANO, 1990). 
A temperatura durante a noite pode variar entre 16 e $20^{\circ} \mathrm{C}$, sendo a mínima, no inverno, de $13^{\circ} \mathrm{C}$ (MEJIAS \& RUANO, 1990).

Como ocorre normalmente com outras suculentas, o solo utilizado deve permitir uma boa drenagem da água e aeração das raízes, já que as plantas facilmente têm suas raízes apodrecidas por umidade excessiva (GRIFFITH JUNIOR, 1998). HERWIG (1976) recomenda seu cultivo em solo arenoso e levemente alcalino.

Para o cultivo comercial, a irrigação deve ser moderada, podendo ser feita pelo método localizado, visando evitar ataque de fungos foliares, e por fertirrigação, aplicando entre 150 e 200 ppm de adubo na razão 1:1:1 (MEJIAS \& RUANO, 1990).

\section{PROBLEMAS FISIOLÓGICOS}

Nas regiões sujeitas a temperaturas abaixo de $0^{\circ} \mathrm{C}$, as folhas podem desenvolver sintomas de branqueamento e encharcamento de uma a quatro semanas após a exposição ao frio. Deve-se, portanto, mantê-las protegidas contra as baixas temperaturas do ar e da água (HENLEY et al., s.d.).

\section{PRAGAS E DOENÇAS}

Poucos são os estudos referentes a pragas e doenças nesse grupo de plantas ornamentais.

\subsection{Pragas}

Os maiores problemas relatados são as lagartas de mariposas e tripes, que podem invadir as estufas a partir de plantas infestantes que possam estar próximas. As lagartas podem ser detectadas pela presença de seus excrementos ou pelo dano que causam, como grandes buracos no centro ou ao longo das bordas das folhas. Já os danos provocados por tripes podem ser folhas enroladas e distorcidas, com cicatrizes cinza-prateado ou calosidades onde o inseto se alimentou; além disso, tripes podem transmitir viroses para muitos espécimes ornamentais (HENLEY et al., s.d.).

\subsection{Doenças}

Entre as doenças observadas em sanseviérias, destacam-se as manchas foliares causadas pelos fungos Fusarium, Colletotrichum e Sclerotium.

Os sintomas causados por Fusarium moniliforme podem surgir, inicialmente, em folhas mais novas. A infecção somente ocorre quando as plantas estão úmidas e os esporos presentes (HENLEY et al., s/d). MEJIAS \& RUANO (1990) acrescentam que baixas temperaturas também favorecem o crescimento desse fungo.

Os sintomas são manchas foliares irregulares, deprimidas, marrom-avermelhadas e, freqüentemente, com bordas amarelas. Se as condições favoráveis ao desenvolvimento do fungo se mantiverem, as lesões podem coalescer e a infecção, espalhar-se até o meristema. O problema pode manter-se apenas em algumas plantas se a umidade for diminuída e a planta, pulverizada com fungicidas (HENLEY et al., s.d.).

PITTA et al. (1990) relataram a ocorrência de plantas afetadas por Colletotrichum gloesporioides com lesões caracterizadas por manchas foliares deprimidas e de bordos nítidos, pardo-escuras, com massas rosadas ao centro, características de seus conídios, cuja disseminação se faz principalmente mediante a água de irrigação. Esse fungo pode ser controlado pela aplicação de fungicidas à base de oxicloreto de cobre, benomyl ou mancozeb, além da eliminação das plantas doentes.

Patógenos como Sclerotium rolfsii podem atacar praticamente a planta toda, mas são mais freqüentemente encontrados em folhas. Inicialmente, os sintomas são caracterizados por encharcamento, lesões necróticas próximas ou exatamente na linha do solo. Um micélio branco pode ser encontrado crescendo na superfície do solo ou sobre as folhas. No início, os esclerócios têm aspecto branco e cotonoso, com o tamanho de uma semente de mostarda. Torna-se, então, de aspecto bronzeado e endurecido, podendo ocasionar murcha e podridão da haste. Esses sintomas também podem aparecer em mudas, nos meses do verão (HENLEY et al., s.d.).

As plantas também podem ser afetadas pela bactéria Erwinia, cujo sintoma começa pelo apodrecimento da base das folhas, podendo destruir toda a planta (MEJIAS \& RUANO, 1990). A incidência de Erwinia carotovora apresenta-se como uma podridão mole na parte mais baixa da muda. Às vezes, as plantas podem apresentar um forte odor, semelhante ao de peixes nas porções apodrecidas, característica comum do ataque dessa bactéria. O método de controle mais adequado é a diminuição da quantidade de água nas folhas e medidas sanitárias rigorosas na propagação. Os bactericidas são pouco eficientes e, por isso, não recomendados (HENLEY et al., s.d.). 


\section{AGRADECIMENTOS}

Os autores agradecem ao pesquisador Dr. Luiz Antonio Ferraz Matthes, que introduziu a coleção de Sansevieria no Instituto Agronômico, Campinas (SP), obtidas, na sua maioria, no Sítio Roberto Burle Marx, em Guaratiba (RJ).

\section{REFERÊNCIAS BIBLIOGRÁFICAS}

ANDREU, R.G. Plantas de interior. 1.ed. Espanha: Editorial Blume, 1975. p.126-127.

BLOSSFELD, H. Jardinagem. São Paulo: Edições Melhoramentos, 1963. p.123.

BUONFIGLIO, M. 2001 Disponível em: <http:// www.terra.com.br/esoterico/monica/ monica_17_10_2001.htm>. Acesso em: out. 2003.

CHAHINIAN, J. The Sansevieria Journal: Euphorbia Journal, v. $6 \& 7,2003$. Disponível em: <http:// web.onyxnet.co.uk/John.Gamesby-AZTEKIUM/ Sansevieria.html>. Acesso em: set. 2003.

DAHLGREN, R.M.T.; CLIFFORD, M.T. \& YEO, P.F. The families of the monocotyledons: estructure, evolution and taxonomy. Springer-Verlag: Berlin, 1985. 520p.

GLAVICH, T. San Gabriel Valley Cactus and Succulent Society: Succulent of the month - november 2001. Disponível em: <http://www.desertsong.com/sgvcss/news/ sotM-11.01.pdf>. Acesso em: abril de 2004.

GRAF, A.B. Exotica: pictorial cyclopedia of exotic plants from tropical and near-tropic regions. 9. ed. New Jersey: Rehrs Company Inc., 1978. 1834 p.

GRIFFITH JUNIOR, L.P. Tropical foliage plants: a grower's guide. Batavia (USA): Ball publishing, 1998. p.268-270.

HARTMANN, H.T.; KESTER, D.E. \& DAVIES JR., F.T. Plant propagation: principles and practices. 5.ed. Englewood Cliffs, New Jersey: Printice-Hall International, Inc., 1990. p.211.
HENLEY, R.W.; CHASE, A.R. \& OSBORNE, L.S. Sansevieria production guide. Apopka: University of Florida, s.d.

HERWIG, R. Viva o verde: o livro das plantas. São Paulo: Círculo do Livro, 1976. p.159.

JOLY, A.B. Botânica: introdução a taxonomia vegetal. 2.ed. São Paulo: Companhia Editora Nacional, 1977. p. 661-663.

LORENZI, H. \& MELLO FILHO, L.E. de. As plantas tropicais de Burle Marx. São Paulo: Instituto Plantarum de Estudos da Flora, 2001, p.297-302.

LORENZI, H. \& SOUZA, H.M. de Plantas ornamentais no Brasil: arbustivas, herbáceas e trepadeiras. 3.ed. Nova Odessa: Editora Plantarum, 2001.

MEDINA, J.C. Plantas fibrosas da flora mundial. Campinas: Instituto Agronômico, 1959. p.269-270.

MEJIAS, R.J. \& RUANO, M.C. El cultivo industrial de plantas en maceta. Reus: Ediciones de Horticultura SL, 1990. p.244-246.

PITTA, G.P.B.; CARDOSO, R.M.G. \& CARDOSO, E.J.B.N. Doenças das plantas ornamentais. IBLC- Instituto Brasileiro do Livro Científico Ltda. São Paulo, 1990. 174p.

TAKAWIRA, R. \& NORDAL, I. The genus Sansevieria (família Dracaenaceae) in Zimbabwe. In: XX EUCARPIA Symposium on New Ornamentals II. Acta Horticulturae, v.572, p.189-199, 2002.

THE LINNEAN SOCIETY OF LONDON. Londres. Botanical Journal of the Linnean Society, v.141, p.399436, 2003.

$<$ http://www.destinos.com.br/sintonia/Plantas que podem melhorar o ambiente. Acesso em: agosto de 2003.

$<$ http://jabasta.net/arq/secoes/jardtopicosdecorativas 03.html>. Acesso em: agosto 2003. 